\title{
Transient stability analysis of two area power system using unified power flow controller
}

Vishwakarma Satyendra

Department of Electrical Engineering, Himalayan Institute of Technology \& Management, Lucknow, Uttar Pradesh, India

Corresponding Author Email: satyendrav89@gmail.com

https://doi.org/10.18280/ama_c.730401

Received: 4 July 2017

Accepted: 15 January 2018

\section{Keywords:}

UPFC, faults, facts, MATLAB simulation

\begin{abstract}
Occurrence of a fault in a power system causes transients. To stabilize the system, Power System Stabilizer (PSS) and Automatic Voltage Regulator (AVR) are used. This paper considers a typical Four-machine eleven-bus system forming two areas connected by two parallel lines as a case study for investigating the performance of UPFC in achieving stability. By using a UPFC the oscillation introduced by the faults, the rotor angle and speed deviations can be damped out quickly. In the study the UPFC is connected in one of the lines and the fault is assumed on the other line. The effectiveness of UPFC in suppressing power system oscillation is investigated by analyzing four oscillations in rotor angles and change in speeds that occurred in the three machine system considered in this work. A MATLAB simulation has been carried out to demonstrate the performance of the UPFC in achieving transient stability of the Four-machine eleven-bus two area system.
\end{abstract}

\section{INTRODUCTION}

In recent years, greater demands have been placed on the transmission network, and these demands will continue to increase because of the increasing number of utility generators and heightened competition among utilities themselves. Added to this is the problem that it is very difficult to acquire new rights of way, increase demands on the transmission, absence of long term planning, and the need to provide open access to generating companies and customers. The continuing rapid development of high-power semiconductor technology now makes it possible to control electrical power systems by means of power electronic devices. The required safe operating margin can be substantially reduced by the introduction of fast dynamic control over reactive and active power by high power electronic controllers. This can make the AC transmission network 'flexible' to adapt to the changing conditions caused by contingencies and load variations. Flexible AC Transmission System (FACTS) is defined as Alternating current transmission systems incorporating power electronic-based and other static controllers to enhance controllability and increase power transfer capability'. The main function of the UPFC is to control the flow of real and reactive power by injection of a voltage in series with the transmission line. Both the magnitude and the phase angle of the voltage can be varied independently. Real and reactive power flow control can allow for power flow in prescribed routes, loading of transmission lines closer to their thermal limits can be utilized for improving transient and small signal stability of the power system. The schematic of the UPFC is shown in Fig.1.

The UPFC consists of two branches. The series branch consists of a voltage source converter, which injects a voltage in series through a transformer. The inverter at the input end of the UPFC is connected in shunt to the AC power system and the inverter at the output end of the UPFC is connected in series with the AC transmission circuit. Since the series branch of the UPFC can inject a voltage with variable magnitude and phase angle it can exchange real power with the transmission line. However the UPFC as a whole cannot supply or absorb real power in steady state (except for the power drawn to compensate for the losses) unless it has a power source at its DC terminals.

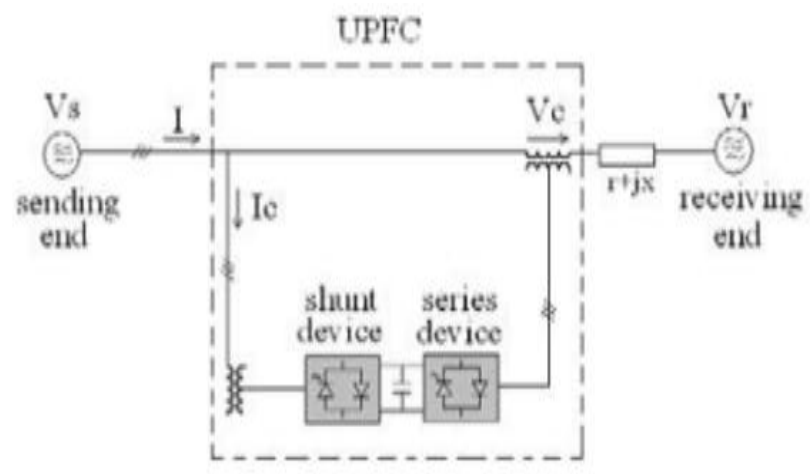

Figure 1. Schematic diagram of UPFC

The UPFC can control the transmission real power, at its series-connected output end, while independently providing reactive power support to the transmission line at its shuntconnected input end. Furthermore, the UPFC can independently control real and reactive power flow along the transmission line at its output end, while providing reactive power support to the transmission line at its input end. It has been shown [2-4] that it is possible to independently control real and reactive power flow at the UPFC input circuit by regulating the DC-link capacitor voltage and varying both the phase angle and the modulation index of the input inverter. The DC-link capacitor voltage $(\mathrm{Vdc})$ is unregulated. 


\section{UNIFIED POWER FLOW CONTROLLER (UPFC)}

The UPFC consists of two voltage source converters, which operate from a common DC- circuit consisting of a DCstorage capacitor. The UPFC could be described as consisting of a parallel and a series branch. Each converter can independently generate or absorb reactive power. This arrangement enables free flow of active power in either direction between the AC terminals of the two converters. The function of the parallel converter is to supply the active power demanded by the series branch. This converter is connected to the Ac terminal through a parallel connected transformer. If required. It may also generate or absorb reactive power, which can provide independent parallel reactive power compensation for the line. The series converter provides the main function of the UPFC by injecting an AC voltage with controllable magnitude and phase angle. The transmission line current flows through this voltage source resulting in an active and reactive power exchange with the system. The active power exchange at the AC terminal is provided by the parallel branch, with the reactive power exchange generated internally by the converter.

In recent years, energy, environment, right-of-way, and cost problems have delayed the construction of both generation facilities and new transmission lines, while the demand for electric power has continued to grow. This situation has necessitated a review of the traditional power system concepts and practices to achieve greater operating flexibility and better utilization of existing power systems [7-10].

During the last two decades, major, if not revolutionary, advances have been made in high-power semiconductor device and control technologies. These technologies have been instrumental in the broad application of high voltage DC transmission and power system inertia schemes, and they have already made a significant impact on AC transmission via increasing the use of thyristor controlled static $\mathrm{VAr}$ compensators (SVCs). Static VAr compensators control only one of the three important parameters (voltage, impedance, phase angle) determining the power flow in AC power systems: the amplitude of the voltage at selected terminals of the transmission line. Among these, the Distribution static compensator (D-STATCOM) and Dynamic Voltage Restorer (DVR) are most effective devices, both of them based on the Voltage Source Converts (VSC) principles [15].

Theoretical considerations and recent system studies [1] indicate that high utilization of a complex, interconnected AC power system, meeting the desired objectives for availability and operating flexibility, may also require the real-time control of the line impedance and the phase angle. Hingorani [1] proposed the concept of flexible AC transmission systems or FACTS, which includes the use of high-power electronics, advanced control centers, and communication links, to increase the usable power transmission capacity to its thermal limit. Within the framework of FACTS, and other efforts with similar objectives, the development of thyristor-controlled series compensators for line impedance control, thyristor controlled tap-changing transformers for phase angle control, and other thyristor controlled devices for dynamic 'brakes' and over voltage suppressors has already been used [3, 4].

Although present static VAr compensators and other thyristor-controlled equipments developed for power flow control (i.e., series compensators and phase shifters) can have the necessary speed for real-time control, they are rather large, custom-designed and fabricated systems of substantial cost, requiring considerable size facility with significant labor installation. For these reasons, it is unlikely that they will be able to provide the long-term, volume-production based economic solution for flexible AC transmission systems. It has long been realized that an all solid-state or advanced, static VAr compensator, which is the true equivalent of an ideal synchronous condenser, is technically feasible [5-8] and, with the use of gate turn-off (GTO), thyristors, is economically viable. The extension of this approach to controllable series compensation and phase shifting has been proposed [5].

So UPFC is the more versatile FACT device, which can provide various types of control such as voltage compensation, phase shifting, real and reactive power compensation. So by using the UPFC the power system transient stability is enhanced by placing it in the bus of the power system, which enhance the power carrying capability and Transient stability of the power system this approach of power transmission control promises simplified system design, reduction in equipment size and installation labor, improvements in performance, and significant reduction in capital cost, fuelled by advances in power semiconductor technology.

\section{SYSTEM INVESTIGATED}

Occurrence of fault may lead to instability in a system or the machine fall out of synchronism. Stability study should be done to analyze the transient stability of the power system. If the system can't sustain till the fault is cleared then the fault will unstable the whole system. If the oscillation in rotor angle around the final position go on increasing and the change in angular speed during transient condition go on increasing then system never come to its final position. The unbalanced condition or transient condition may lead to instability where the machines in the power system fall out of synchronism. Calculation of load flow equation by Newton Raphson method, or decoupled method gives the rotor angle and initial condition.

Describe the system studies and carried out using the simulation on matlab.

(1) Without UPFC study of steady state analysis of two area system.

(2) Study of waveform without UPFC and with fault.

(3) With UPFC study of steady state analysis of two area system.

(4) Study of waveform with UPFC with fault.

For studying transient stability performance of multimachine power system the model shown in Figure 1 is considered [10]. Each synchronous generator of the multi machine system and UPFC are simulated. The text system consists of two fully symmetrical areas linked together by two $220 \mathrm{kv}$ lines of $220 \mathrm{~km}$ length. It is specially designed to study low frequency electromechanical oscillations in large interconnected power systems. Each area is equipped with two identical round rotor generators rated 20kV/900MVA. The synchronous machine has identical parameters, except for inertias which are $\mathrm{H}=6.5 \mathrm{~s}$ in area 1 and $\mathrm{H}-6.175 \mathrm{~s}$ in area 2. Thermal plants having identical speed regulators are further assumed at all locations, in addition to fast static exciters with a 200 gain. The load is represented as constant impedances and split between the areas in such a way that area 1 is exporting $413 \mathrm{MW}$ to area 2. Since the surge impedance loading of a single line is about $140 \mathrm{MW}$, the system is somewhat stressed, even in steady state. The results are seen by POWER GUI and selecting the LOAD FLOW INITIALIZTION 


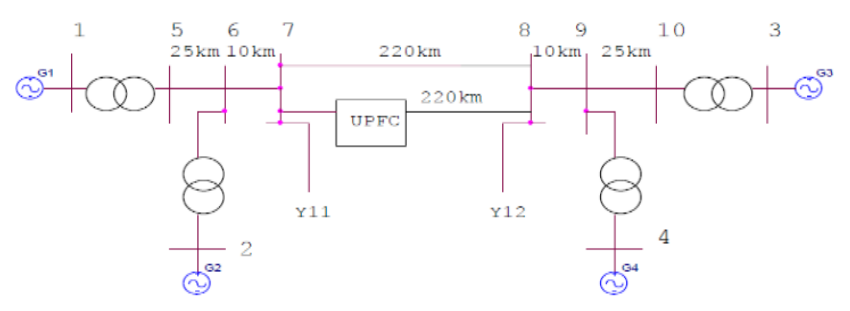

Figure 2. System model

For this purpose MATLAB simulation software package version 8.5 is used, A typical 4 generator 11 bus test system chosen to model which consists of generators, loads, three phase transmission lines, and three phase two winding transformers. System parameters provided in Appendix. A set of simulation tests was carried to test UPFC implemented using MATLAB. Simulations run for duration of $50 \mathrm{sec}$. Three phase ground fault applied in between bus $7 \&$ bus 8 of one transmission line at $4 \mathrm{sec}$ with duration of $0.1 \mathrm{sec}$. Here in this text system, UPFC is connected on weak tie lines between bus 8 an bus 9 in order to enhance the transient stability of the multi area system. Here different conditions have been assumed.

\subsection{For the following conditions}

The system was studies as under following condition:

(1) Without UPFC study of steady state analysis of two area system.

(2) Study of waveform without UPFC and with fault with PSS $=0$

(3) With UPFC study of steady state analysis of two area system.

(4) Study of waveform with UPFC without load and with fault PSS $=0$

System investigated in the matlab simulation: Here area 1 and area 2 are symmetrical areas and are connected by two weak tie lines. Area 2 of the system was symmetrical to the area 1. The Simulink representation of area I is shown in next fig 3 .

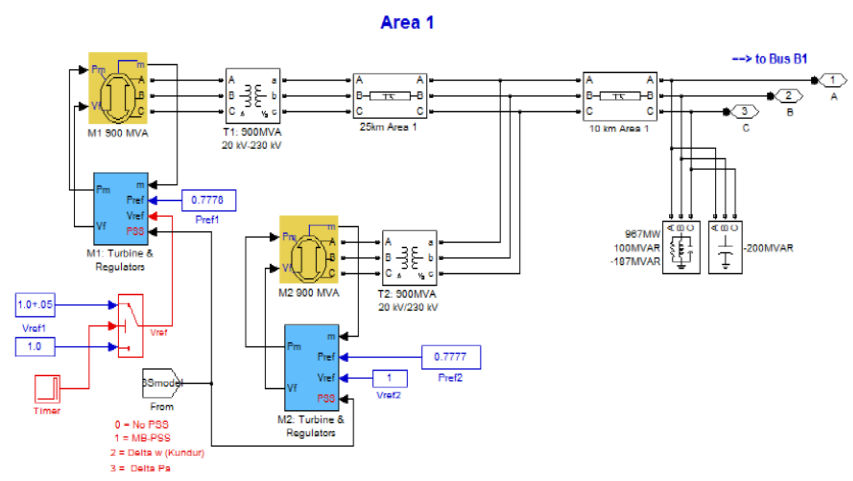

Figure 3. Area 1 of symmetrical areas of two area power system
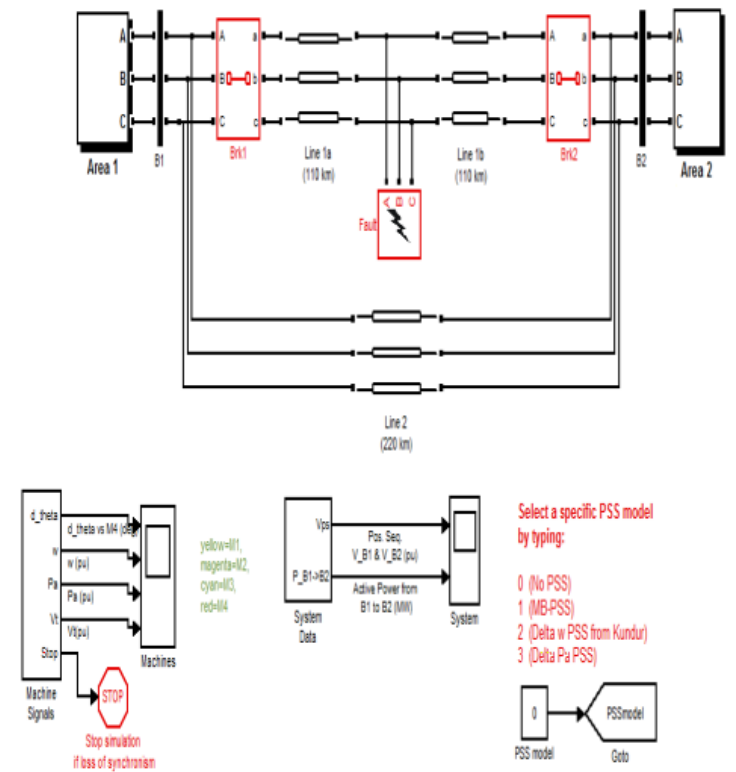

Figure 4. Simulink representation of the test model without UPFC

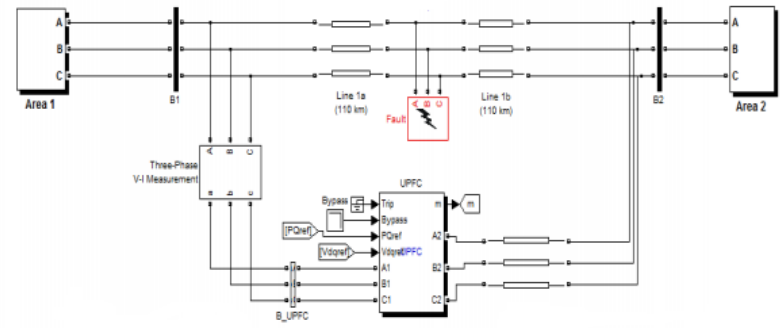

Figure 5. Simulink representation of the test model with UPFC

The above fig 4 and fig. 5 show the simulink representation of the system model with and without UPFC.

\section{SIMULATION RESULTS}

\subsection{Without UPFC, without fault}

The MATLAB simulation result of the power system is shown in the figure given below. First taking the case when UPFC is not connected in the system and if when fault is not there, system is going to stable region. The following curves show the behavior of the system without UPFC.

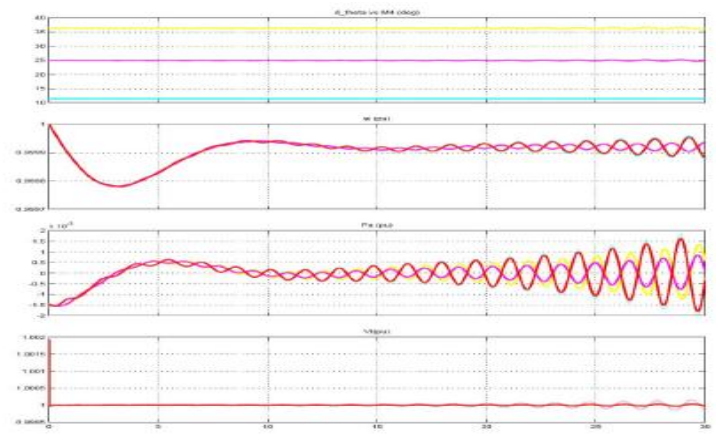

Figure 6. Under normal (steady state) Condition machine waveform without fault 


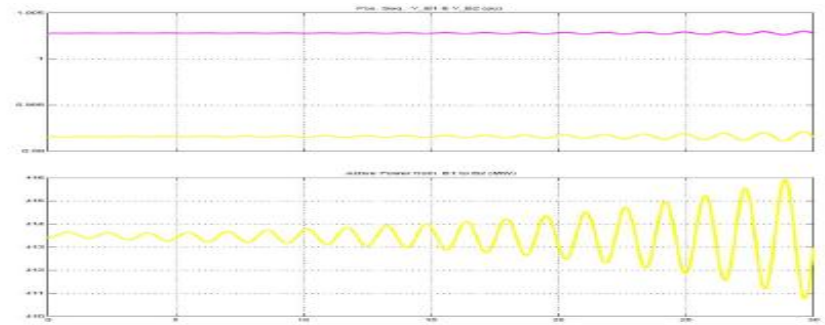

Figure 7. Under steady state Condition power waveform

\subsection{Without UPFC and with fault}

The MATLAB simulation result of the power system is shown in the figure given below. Taking the case when UPFC is not connected in the system and if when fault is there, system is going to unstable region. The following curves show the behavior of the system without UPFC. Fig 8 is acceleration power, fig. 9 show the power transfer from area B1 to area B2.
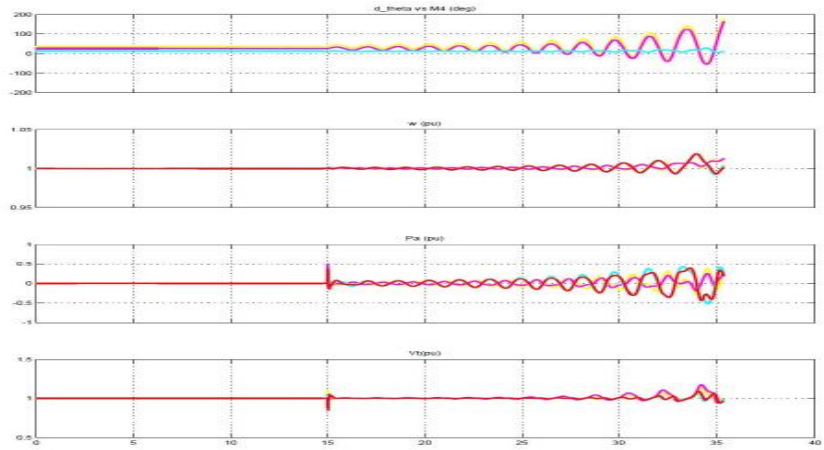

Figure 8. Under fault Condition machine waveform

Fault- transition time $[1515+6 / 60]$,

Ckb1-transition time- $[15+2 / 6015+7 / 60]$

Ckb2-transition time-[15+2/60 15+7/60]

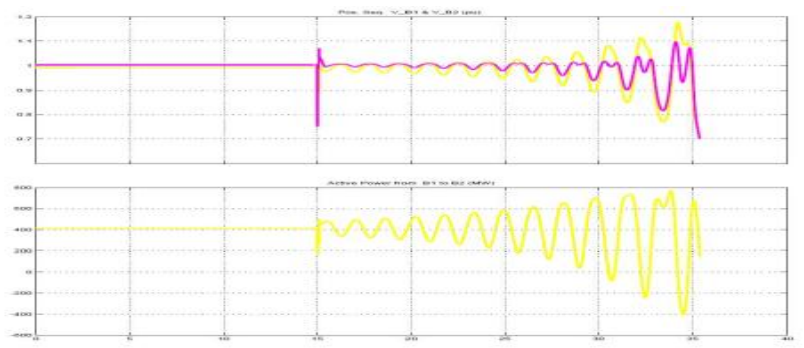

Figure 9. Under fault Condition power waveform

Fault- transition time- $[1515+6 / 60]$,

Ckb1-transition time- $[15+2 / 6015+7 / 60]$

Ckb2-transition time- $[15+2 / 6015+7 / 60]$

\subsection{With UPFC, without fault}

The MATLAB simulation result of the power system is shown in the figure given below. First taking the case when UPFC is connected in the system and if when fault is not there, system is going to stable region. The following curves show the behavior of the system without UPFC. Fig 10 is acceleration power, fig. 11 show the power transfer from area $\mathrm{B} 1$ to area $\mathrm{B} 2$.
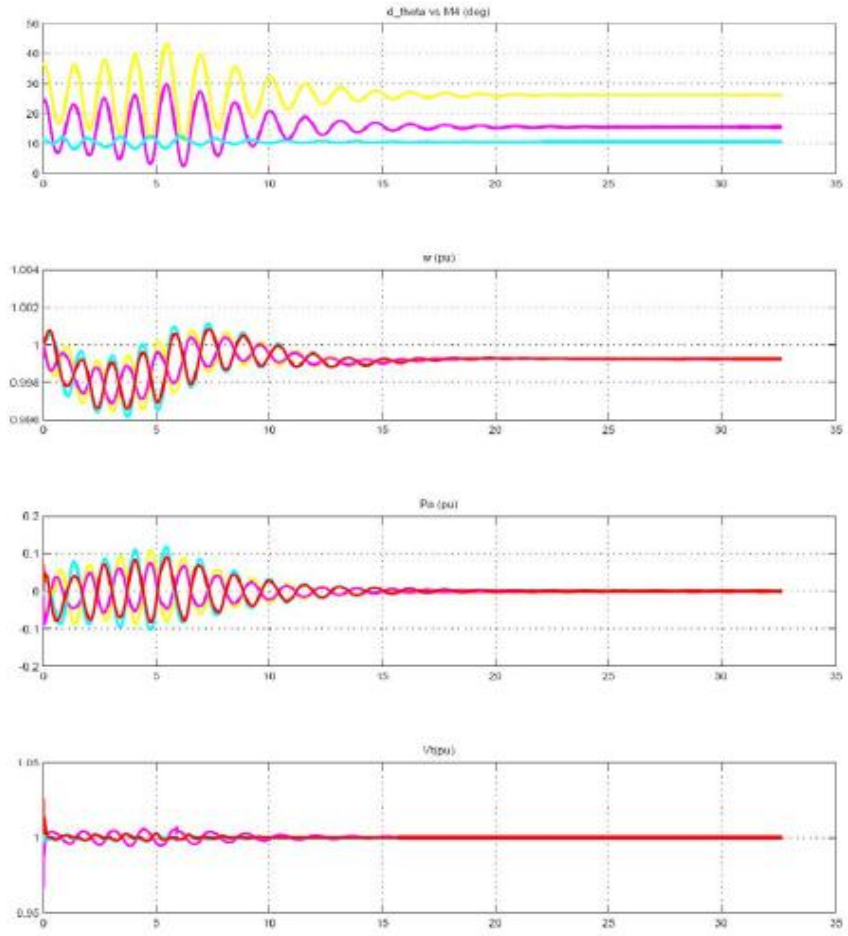

Figure 10. Under steady state Condition machine waveform without fault Pref. -Time [0 10]

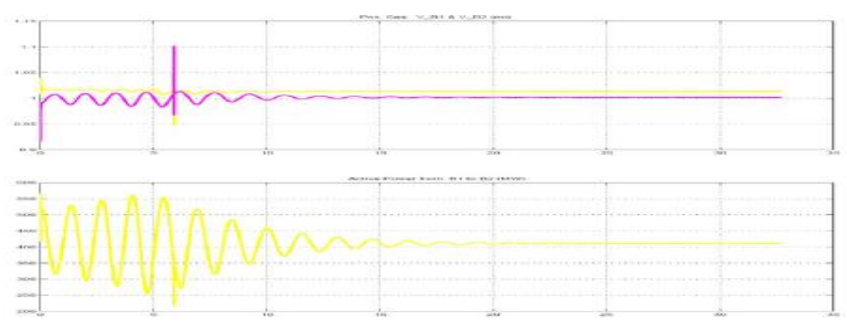

Figure 11. Under normal condition power transfer without fault Pref. -Time [0 10], Amp [2.07 2.07]

\subsection{With UPFC, with fault}
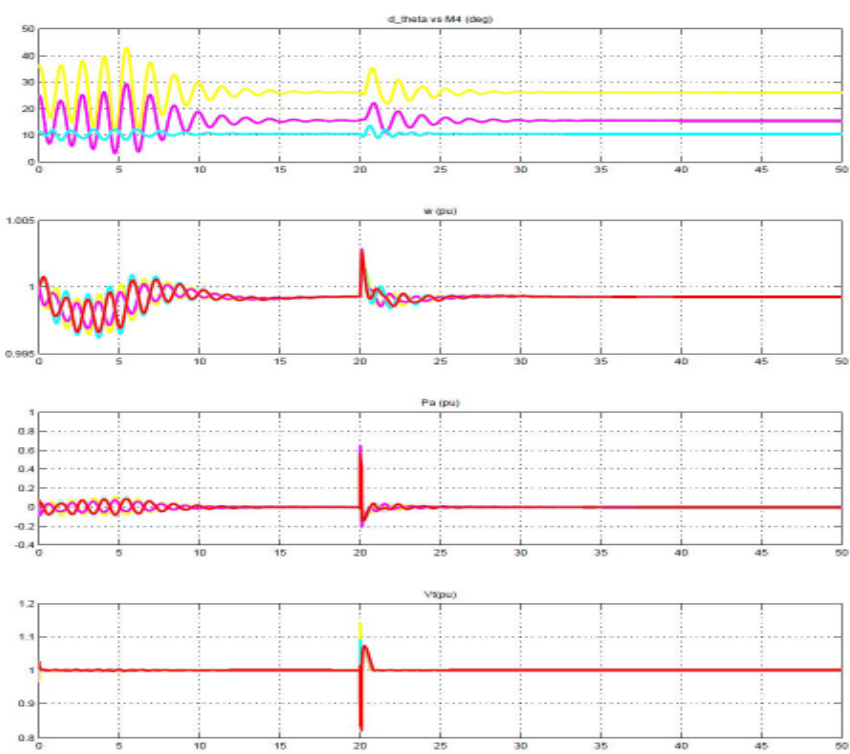

Figure 12. Under fault Condition machine waveform Pref. Time [0 10], Amp [2.07 2.07], Amp [1 0] Fault- Transition Time [20 20+6/60] 

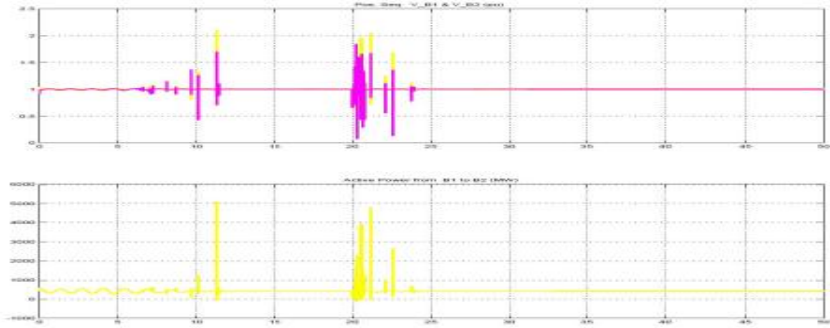

Figure 13. Under fault Condition power waveform with Pref. - Time [0 10]

Fault -Transition Time [20 20+6/50]

The MATLAB simulation result of the power system is shown in the figure given below. First taking the case when UPFC is connected in the system and fault is also there, system is going to unstable for a certain period of time. After fault clear from the system UPFC helps the system going to stable state. The following curves show the behavior of the system without UPFC. Fig 12 is acceleration power, fig. 13 show the power transfer from area B1 to area B2.

\section{CONCLUSION}

In this paper, an overview of transient stability analysis of two area power system is presented. At first a theoretical review of transient stability in two area power system without UPFC, considered study state condition and fault condition, which can be easily implemented in MATLAB is developed. Secondly, a theoretical review of enhancement of transient stability in two area power system with UPFC considered

1. Study state condition and 2. Fault Condition, Transient stability is intended for without change the syndromous Generator parameter and load.

A MATLAB simulink model for the enhancement of transient stability technique with both without UPFC and with UPFC is developed. In the simulation result for:

1. Test System without UPFC for large signal perturbation.

2. Test system with UPFC for large perturbation.

The simulation result are analyze and found that the result obtained from the test system is having large transient during large signal perturbation in case of without UPFC, therefore system goes into out of synchronism. In without UPFC two area system the system is unstable, when the gain of the excitation (Voltage Controller) in high (normal). Again the result obtained from the two area power system with UPFC is having improvement of transient stability during large signal perturbation therefore system stability \& reliability increases.

\section{REFERENCES}

[1] Hingorani G, Gyugyi L. (2000). Understanding FACTS: concepts and topology of flexible transmission system. IEEE Press, New York.

[2] Kundur P. (1994). Power System Stability and Control. New York: McGraw Hill.

[3] Papic I, Zunko O, Povh D, Weinhold M. (1997). Basic control of unified power flow controller. IEEE Transactions on Power Systems 12(4). https://doi.org/10.1109/59.627884

[4] Papic I. (2000). Mathematical analysis of FACTS devices based on a voltage source converter- Part II.
Electric Power System Research 56: 149-157. https://doi.org/10.1016/S0378-7796(00)00112-7

[5] Gyugyo L. (1992). Unified power flow control concept for flexible Ac Transmission systems. IEE proc. C 4(139): 323-331. https://doi.org/10.1049/ip-c.1992.0048

[6] Gyugyo CD, Williams SL, Rietman TR, Edris A, Schauder CD, Torgerson DR. (1995). The unified power flow controller: A new approach to power transmission control. IEE Trans on Power Delivery 10(4): 1085-1097. https://doi.org/10.1109/61.400878

[7] Nabavi Niaki A, lravani MR. (1996). Steady-state and dynamic models of Unified power flow controller (UPFC) for power system studies. IEEE Trans. on Power Systems 11(4): 1937-1943. https://doi.org/10.1109/59.544667

[8] Padiyar KR, Kulkarni AM. (1978). Control design and simulation of unified power flow controller. IEEE Transactions on Power Delivery 13(4): 1348-1354. https://doi.org/10.1109/61.714507

[9] Tambey N, Kothari ML. (2003). Damping of power system oscillations with unified power flow controller (UPFC). IEE Proc. - C 150(3): 129-140. https://doi.org/10.1049/ip-gtd:20030114

[10] Menniti D, Pinnarelli A, De Martinis U, Andreotti A. Modelling of Unified Power Flow Controller into Power Systems using P-Spice.

[11] Makombe T, Jenkins N. (1999). Investigation of a unified power flow controller. IEE proc.- C 146(4): 400408. https://doi.org/10.1049/ip-gtd:19990037

[12] Papic I, Zunko P. (2003). UPFC converter-level control system using internally calculated system quantities foe decoupling. International Journal of Electrical power and Energy Systems 25: 667-675. https://doi.org/10.1016/s0142-0615(03)00025-5

[13] Canizares C, Uzunovic E, Reeve J. (2004). Transient stability and power flow models $\mathrm{O}$ the unified power flow controller for various control strategies" technical report \#2004-09. University of Waterloo. E\&CE, March 2004.

[14] Noroozian M, Angquist L, Ghandari M, Anderson G. (1997). Use of UPFC for optimal power flow control. IEEE Trans. On Power Delivery 12(4): 1629-1634. https://doi.org/10.1109/61.634183

[15] Mithlesh S. (2014). Fuzzy based simulation of DSTATCOM and DVR in power systems. AMSE Journals -2014-Series: Modelling A 87(2): 1-18.

\section{APPENDIX-A}

\section{System Data:}

Area (1) and area (2) are symmetrical areas

1. Alternator:- four alternators

i. Nominal base- 900MVA

ii. Nominal voltage- $20 \mathrm{kV}$

2. Transformers:-

i. Nominal base- 900MVA

ii. Nominal voltage- $20 / 230 \mathrm{kV}$

3. Transmission lines:-

i. Short line (upto $25 \mathrm{kms}$ )

ii. Long line (more than $25 \mathrm{kms}$ )

4. UPFC:-
i. Nominal Ac voltage- $500 \mathrm{kV}$
ii. Nominal DC voltage- $40 \mathrm{kV}$
iii. Rated power- $100 \mathrm{MVA}$ 